\title{
THE EMPIRICAL ANALYSIS OF SOIL LIQUEFACTION IN IMOGIRI SITE, YOGYAKARTA, INDONESIA
}

\author{
Lindung Zalbuin Mase
}

\begin{abstract}
Dosen Program StudiTeknik Sipil, Fakultas Teknik,Universitas Bengkulu, Jl. W.R. Supratman, KandangLimun, Bengkulu 3837, Email: lmase@unib.ac.id
\end{abstract}

\begin{abstract}
ABSTRAK
A strong earthquake with magnitude of $6.3 M_{w}$, which was later known as the Jogja Earthquake, occurred in the southern part of Yogyakarta Special Province. The earthquake had resulted in the huge damage to the buildings, public facilities as well as triggering the ground failure phenomenon, which was known as liquefaction. An empirical analysis using the conventional method was performed to investigate the liquefaction severity for the site investigation data in Imogiri, a site with the high-level of the liquefaction damage during the earthquake. The peak ground accelerations varied to 0.3 to $0.4 \mathrm{~g}$ are also imple mented in the analysis. The results show that the investigated site is dominated by sandy soils. The sandy soil in Imogiri site is categorised as the liquefiable layer during the Jogja Earthquake and potentially to liquefy on shallow depth. In general, this study could warn the people for the impact of soil liquefaction if the stronger earthquake happens in the future.
\end{abstract}

Keywords :likuifaksi, le mpuing, PGA krit is

\section{INTRODUCTION}

A strong earthquake with the magnitude of 6.3 $M_{w}($ Figure 1) triggered by Opak Fault, occurred in the Yogyakarta Special Province. This earthquake was later known as the Jogja Earthquake. The earthquake had triggered the massive damage to the southern to eastern part of Yogyakarta Special Province. Yogatamaand Fathani (2013) and Setyabudi(2013) reported that the earthquake also resulted in liquefaction along the watershed area of Opak River and several locations in the Bantul Regency and Yogyakarta City, which was dominated by sandy soils with low ground water level. Mase et al. (2013) stated that one of the impacted areas along Opak River is Imogiri site. Based on the previous studies, a study of soil liquefaction in Imog iri Site is intensively performed.

This study presents the empirical analysis of soil liquefaction in Imogiri Site by considering the Jogja Earthquake using the conventional method proposed by Seed and Idriss (1971). Several analyses considering the variation of peak ground acceleration (PGA) are presented. In general, this study is expected to present the liquefaction potential in the site, especially related to the factor of safety and liquefaction probability. This study is also addressed to people to reconsider the liquefaction impact for the building design in Imogiri Site.

\section{LITERATURE REVIEW}

Liquefaction is a unique phenomenon due to the excess pore water pressure during the earthquake, which was resulted in the reduction of effective stress. Once the effective stress reaches zero, the soil particles behave as liquid and the bearing capacity of the soil suddenly disappears.

Several methods had been proposed to estimate the liquefaction potential. One of them is the empirical method using the site investigation data, such as standard penetration test (SPT) and cone penetration test (CPT). The concept of the empirical method is the comparison of the cyclic resistance ratio $(C R R)$ of the soil and the cyclic stress ratio $(C S R)$ due to the earthquake.

Seed and Idriss(1971) proposed the formulation of $C S R$, which depends on peak ground acceleration (PGA), soil effective and total stresses, and depth reduction factor. CSR is expressed in this following equation,

$C S R=0.65 \cdot r_{d} \cdot\left(\frac{\sigma_{v}}{\sigma_{v}^{\prime}}\right)\left(\frac{a_{\max }}{g}\right)$

where, CSR is cyclic stress ratio, $r_{d}$ is depth reduction factor, which was defined as $1-0.012 z$ ( $z$ is the investigated depth), $\sigma_{v}{ }^{\prime}$ is the soil effective stress, $\sigma_{v}$ is the soil total stress, $a_{\max }$ is peak ground acceleration, and $g$ is gravity acceleration.

$C R R$ is a ratio, which is expressed the soil resistance provided by the soil element to retain from the cyclic load due to the earthquake. Seed and Idriss(1971) proposed the graph of CRR corresponding to the corrected SPT $\left(\mathrm{N}_{1}\right)_{60}$, as shown in Figure 2. 
From Figure 2, the value of $C R R$ can be estimated. Furthermore, the value of $C R R$ together with $C S R$ calculated from Equation 1 is used to determine the Factor of Safety against liquefaction $\left(F S_{L}\right)$, which is expressed in Equation 2.

$$
F S_{L}=\frac{C R R}{C S R}
$$

Liquefaction potentially occurs when $F S_{\mathrm{L}}$ is larger or equal to 1 and vice versa.

Equation 2 is used to estimate the liquefaction potential for the earthquake with magnitude of 7.5 $M_{w}$. Therefore, the magnitude scaling factor $(M S F)$ should be implemented in the calculation to estimate Factor of Safety $(F S)$ for the earthquake with the different magnitude. the $F S$ formulation for the different earthquake magnitude, except 7.5 $M_{w}$ can be estimated by this following equation,

$$
\begin{aligned}
& F S_{L}=\frac{C R R \cdot M S F}{C S R} \\
& M S F=\frac{10^{2.24}}{M_{w}^{2.56}}
\end{aligned}
$$

where, $M_{w}$ is the earthquake magnitude

Corresponding to $F S_{L}$, the probability of liquefaction or $P_{L}$ can be determined by using the empirical approach. One of the empirical approach to estimate probability liquefaction is proposed by Cheng and Juang(2000) as expressed in Equation 4 below,

$$
P_{L}=\frac{1}{1+\left(\frac{F S}{1.25}\right)^{3.76}}
$$

where, $P_{L}$ is probability of liquefaction.

\section{III.METHOD OF RESEARCH}

This study is initiated by performing the site investigation in Imogiri Site. A SPT test is performed in the location near the Opak River, which experienced lateral spreading during the Jogja Earthquake in 2006 (presented in Figure 1).Furthermore, the data interpretation is conducted to get the description of soil profile as well as the soil resistance, especially in terms of SPT-N (N). The data analysis including the calculation of corrected SPT or $\left(\mathrm{N}_{1}\right)_{60}$. A study of the characteristic of the Jogja Earthquake is also performed, especially related to the magnitude of the earthquake, the type of earthquake, and PGA. In this study the peak ground acceleration or PGA of the earthquake is varied to be $0.3 \mathrm{~g}, 0.35 \mathrm{~g}$, and $0.4 \mathrm{~g}$. Those are considered based on Fathani et al.(2008) study, which was conducted to estimate PGA during the Jogja Earthquake
After the necessary information is obtained, the calculation for $C S R$ and $C R R$ is performed using the Equations 1 to 4 . The prediction of probability of liquefaction is estimated using Equation 5.

In this study, the interpretation of factor of safety and probability of liquefaction for each investigated depth corresponding to is presented.

\section{RES ULTS AND DIS CUSSION}

The result of site investigation data in the study area (Imogiri Site) is presented in Figure 3.In general, Imogiri site is do minated by sandy soils classified as SP and SM. The soil resistance, in terms of $\left(\mathrm{N}_{1}\right)_{60}$, varied from 8 to $30 \mathrm{blows} / \mathrm{ft}$. The ground water level was found at $0.7 \mathrm{~m}$ deep.

Corresponding to the data presented in Figure 3, the analysis of liquefaction potential is conducted. The interpretation of factor of safety against liquefaction on the Imogiri Site is presented in Figure 4. In Figure 4, the variation of PGA is capable to influence the liquefaction potential for the site. The increase of peak ground acceleration means the decrease of factor of safety. Figure 4 also shows that for PGA of $0.4 \mathrm{~g}$, all investigated depth could be possible to undergo liquefaction. For PGA of $0.3 \mathrm{~g}$, the depth of 10 to $12 \mathrm{~m}$ and the depth of 0 to $2 \mathrm{~m}$ are very vulnerable to undergo liquefaction. Meanwhile, for PGA of $0.35 \mathrm{~g}$ the depth of 0 to $16 \mathrm{~m}$ could be liquefied.

Figure 5 presents the interpretation of probability of liquefaction corresponding to the investigated depth. Consistent with factor of safety against liquefaction, the lower probability of liquefaction means the higher factor of safety. Figure 5 also shows that at the depth of $2 \mathrm{~m}$ and the depth of $12 \mathrm{~m}$, the possibility for liquefaction to happen is very high, since the probabilities to undergo liquefaction are approaching one. 


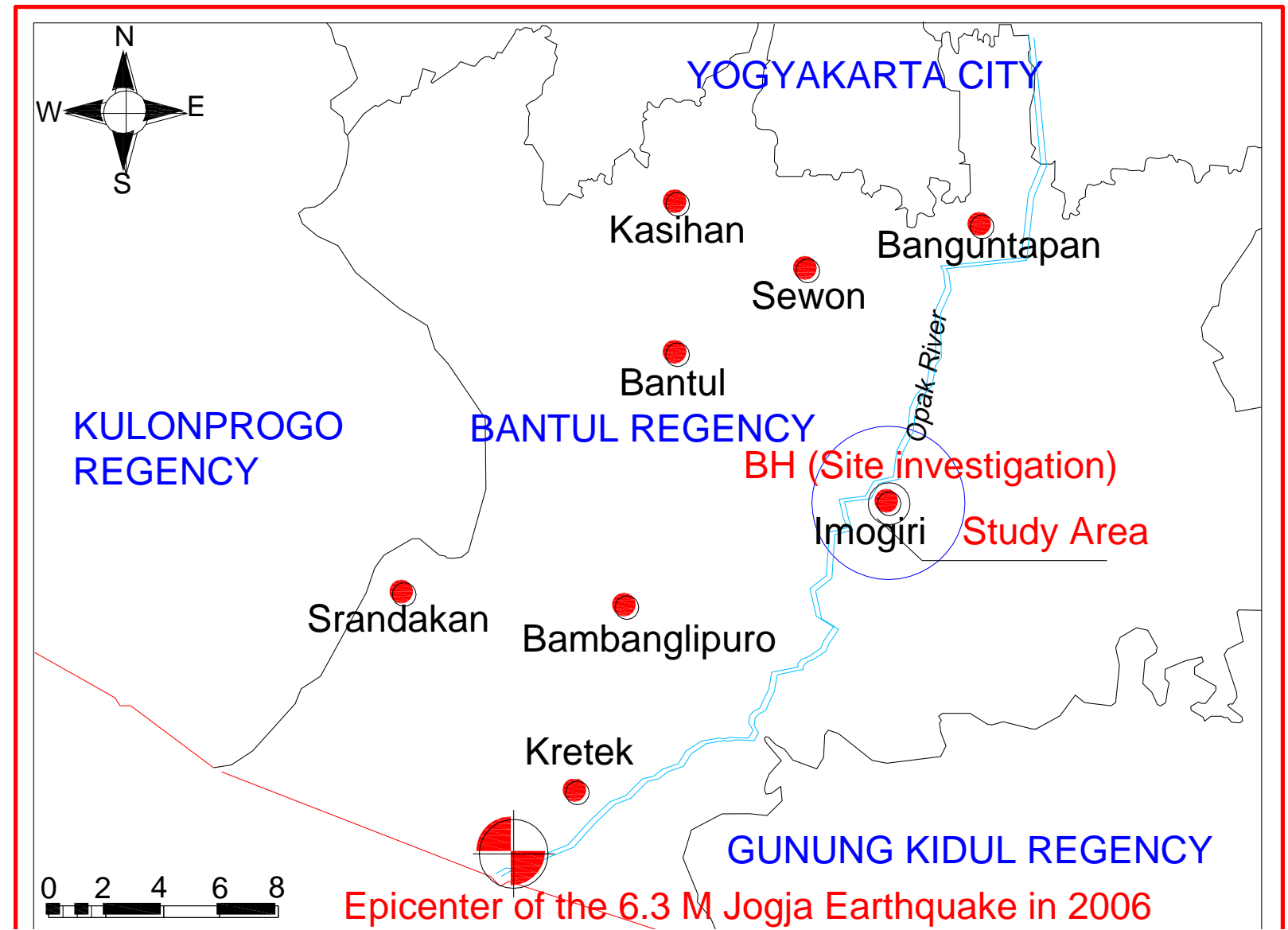

Figure 1. The locations of earthquake epicenter in 2006, site investigation (redraw and modifie from Yogatama (2013)

To investigate the critical condition of Imogiri site during the earthquake to undergo liquefaction, the graphical analysis is performed. In this study, the critical condition is assumed as the condition where the factor of safety against liquefaction is equal to 1 . The interpretation of factor of safety corresponding to probability of liquefaction is presented in Figure 6. In Figure 6, the critical condition could happen when the probability of liquefaction approaches 0.7 . Linking to Figure 6, the estimation of soil resistance for resistance could be estimated, as shown in Figure 7. In Figure 7, the critical condition signed by the probability of liquefaction about 0.7 could happen for the soil with the soil resistance about 23 to $28 \mathrm{blows} / \mathrm{ft}$.

The range of that soil resistance about 23 to 28 blows/ft represents the medium to dense sand. It shows that the energy of the Jogja Earthquake is quite large since it can be possible to trigger liquefaction on medium-dense sand. Therefore, the soil improvement to these layers should be implemented. This is destined to reduce the possibility for this layer to liquefy, especially if the stronger earthquake happens in the future.

\section{CONCLUDING REMARKS}

Imogiri Site is dominated by sandy soils with relatively shallow ground water level.The peak ground acceleration about $0.3 \mathrm{~g}$ to $0.4 \mathrm{~g}$ is very possible to trigger liquefaction at the investigated depth. At the depth of $2 \mathrm{~m}$ and the depth of 12, the probability to undergo liquefaction is very high.During the earthquake, the critical condition, i.e. $F S=1$, could occur when the probability of liquefaction is about 0.7 . The medium to dense sand layers seems to be the vulnerable layer to undergo the critical condition during the Jogja Earthquake.

\section{ACKNOWLEDGEMENT}

The authors would like to thank the Laboratory of Soil Mechanics in Gadjah Mada University for the site investigation data. 


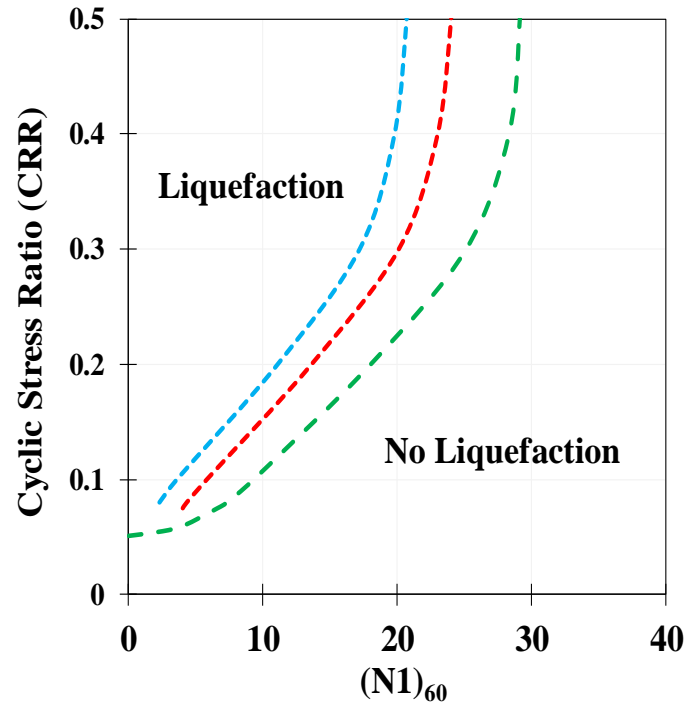

\section{- - CRR Curve for FC $<5 \%$ (Seed and Idriss [4]) \\ --.CRR Curve for 5\%<FC $<15 \%$ (Seed and Idriss [4]) \\ -. CRR Curve for $\mathrm{FC}<35 \%$ (Seed and Idriss [4])}

Figure 2. Relationship for $C R R$ and $\left(\mathrm{N}_{1}\right)_{60}$ [redraw from 4$]$

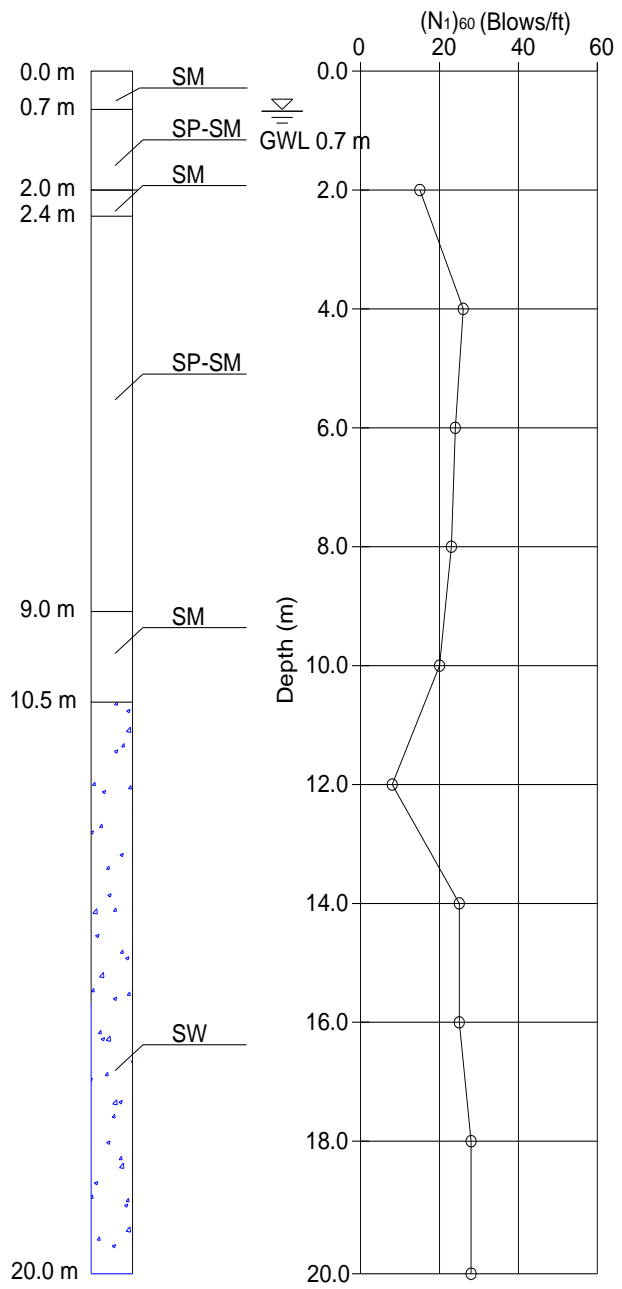

Factor of Safety (FS)

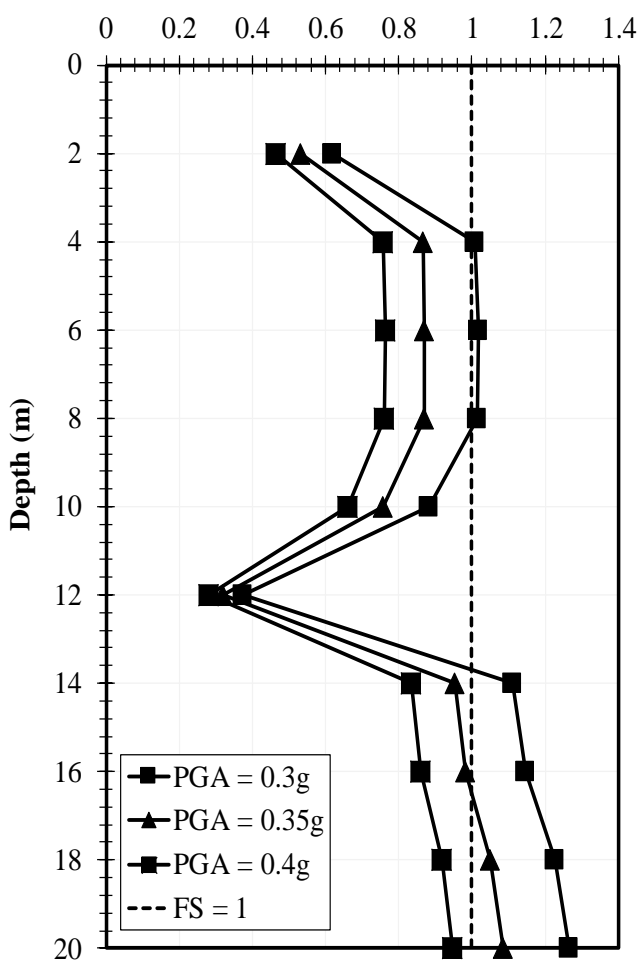

Figure 4. Factor of safety against liquefaction in Imogiri Site

Probability of Liquefaction (PL)

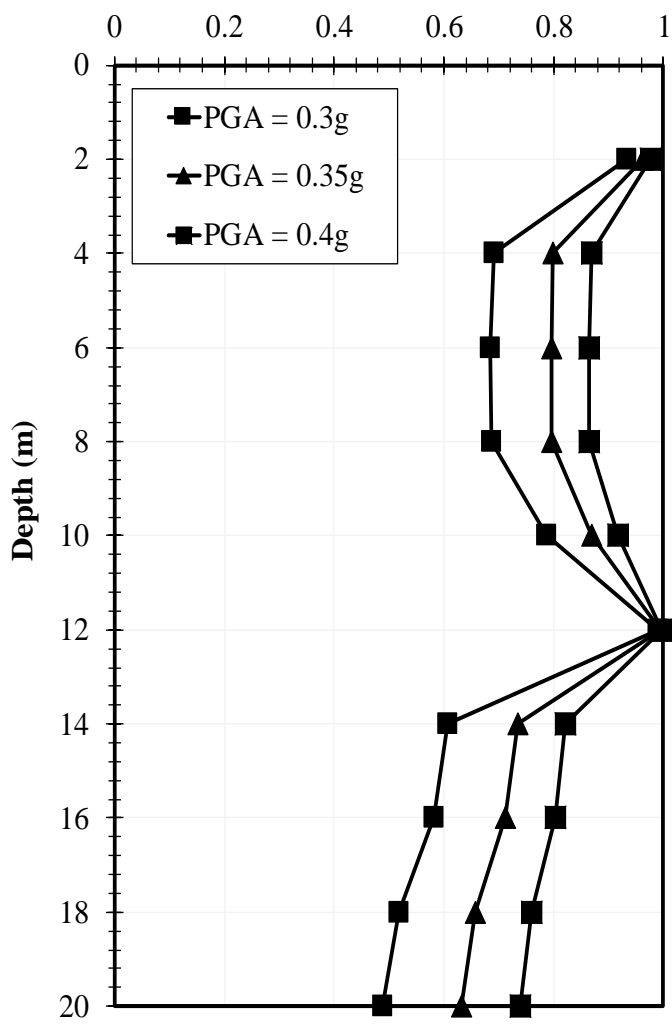

Figure 5. Factor of safety against liquefaction in Imogiri Site

Figure 3. Site investigation data in Imogiri Site 


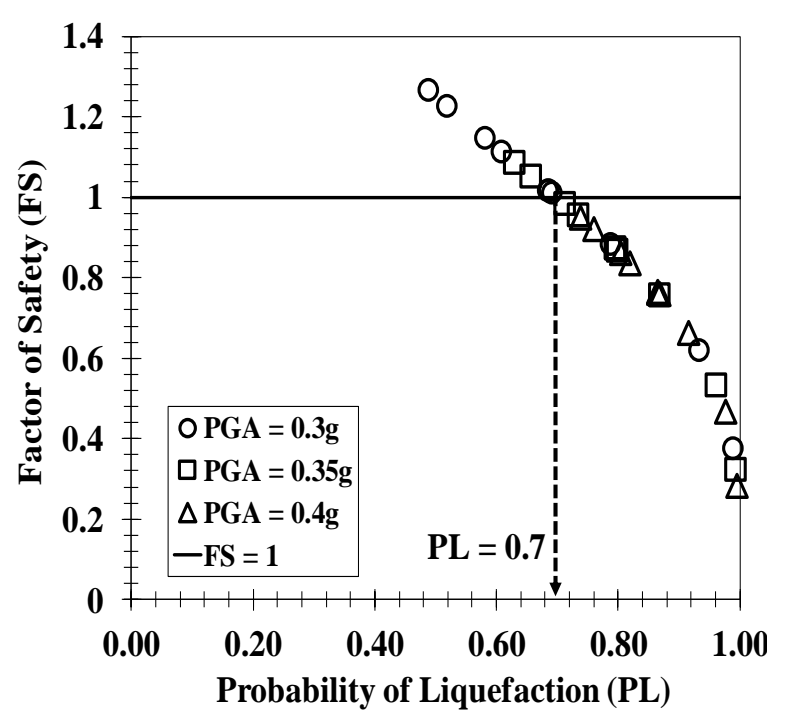

Figure 6. Factor of safety versus probability of liquefaction in Imog iri Site

\section{REFERENCES}

Chen, C.J., and Juang, C.H. 2000, Calibration of SPT-CPT based liquefaction Evaluation Methods, Innovations Applications in geotechnical site characterization, ASCE 97 (Special Edition), pp. 49-64.

Fathani, T.F., Adi, A.D., Pramumijoyo, S., Karnawati, D., 2008. The Determination of Peak Ground Acceleration at Bantul Regency, Yogyakarta Province, Indonesia, The Yogyakarta Earthquake 2006, Karnawati, D., Pramumijoyo, S., Anderson, R., Husein, S., (eds), pp. 12-1 - 12-15.
Mase, L.Z. Fathani, TF, and Adi, A.D. 2013. Experimental Study of Liquefaction Potential in Onak River Imogiri. Yogvakarta. In: Proceedings of the 17th Annual Scientific Meeting of the Indonesian Geotechnical Engineering Society, Jakarta, 13-14 November, Indonesia, pp. 199-20

Seed, H.B. and Idriss, I.M., 1971. Simplified Procedure for Evaluating Soil Liquefaction Potential, Soil Mechanics and Foundations Division ASCE, 97 (SM9), pp. 1249-273, 1971.

Sety abudi A.P., Probability of Liquefaction Analy sis using the Method of Severity Index for Bantul and Sleman Regencies, and Yogyakarta City. 2014. Final Project for Bachelor's Degree, Civil Engineering, Gadjah Mada University, Indonesia

Yogatama. B.A.. Fathani. T.F.. 2013. Liauefaction Potential Analysis on Bantul Regency and Yogyakarta City Area. In: Proceedings of the 17th Annual Scientific Meeting of the Indonesian Geotechnical Engineering Society, Jakarta, 13-14 November, Indonesia, pp. 206211

Yogatama, B.A., 2012. Liquefaction Potential Analysis in Bantul Regency and Yogyakarta City. Final Project for Bachelor's Degree, Civil Engineering, Gadjah Mada University, Indonesia 